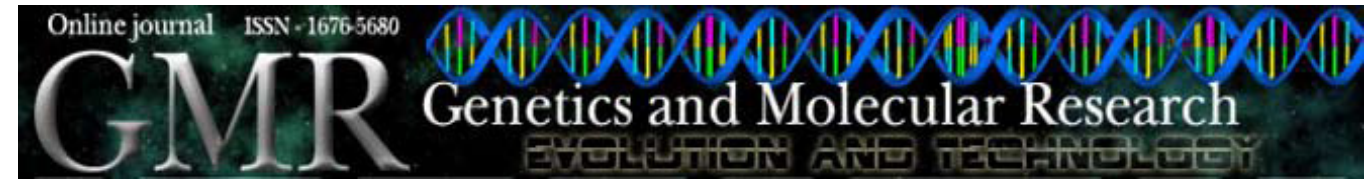

\title{
Expression analysis of transcription factors from the interaction between cacao and Moniliophthora perniciosa (Tricholomataceae)
}

\author{
M.A. Lopes ${ }^{1,2}$, B.T. Hora Junior ${ }^{1}$, C.V. Dias ${ }^{1}$, G.C. Santos ${ }^{1}$, K.P. Gramacho ${ }^{3}$, \\ J.C.M. Cascardo ${ }^{1}$, A.S. Gesteira ${ }^{1,4}$ and F. Micheli ${ }^{1,5}$ \\ ${ }^{1}$ Laboratório de Genômica e Expressão Gênica, \\ Departamento de Genética e Biologia Molecular, \\ Universidade Estadual de Santa Cruz, Ilhéus, BA, Brasil \\ ${ }^{2}$ Departamento de Ciências Biológicas, \\ Universidade Estadual de Feira de Santana, Feira de Santana, BA, Brasil \\ ${ }^{3}$ Comissão Executiva do Plano da Lavoura Cacaueira, Itabuna, BA, Brasil \\ ${ }^{4}$ Embrapa Mandioca e Fruticultura Tropical, Cruz das Almas, BA, Brasil \\ ${ }^{5}$ CIRAD, UMR DAP, Montpellier Cedex 5, France \\ Corresponding author: F. Micheli \\ E-mail: fabienne.micheli@cirad.fr
}

Genet. Mol. Res. 9 (3): 1279-1297 (2010)

Received March 18, 2010

Accepted May 10, 2010

Published July 6, 2010

DOI 10.4238/vol9-3gmr825

\begin{abstract}
Cacao (Theobroma cacao) is one of the most important tropical crops; however, production is threatened by numerous pathogens, including the hemibiotrophic fungus Moniliophthora perniciosa, which causes witches' broom disease. To understand the mechanisms that lead to the development of this disease in cacao, we focused our attention on cacao transcription factors (TFs), which act as master regulators of cellular processes and are important for the finetuning of plant defense responses. We developed a macroarray with 88 TF cDNA from previously obtained cacao-M. perniciosa interaction libraries. Seventy-two TFs were found differentially expressed between the susceptible (Catongo) and resistant (TSH1188) genotypes and/or during the disease time course - from $24 \mathrm{~h}$ to 30 days after infection. Most of the differentially expressed TFs belonged to the bZIP, MYB
\end{abstract}


and WRKY families and presented opposite expression patterns in susceptible and resistant cacao- $M$. perniciosa interactions (i.e., upregulated in Catongo and down-regulated in TSH1188). The results of the macroarray were confirmed for bZIP and WRKY TFs by realtime PCR. These differentially expressed TFs are good candidates for subsequent functional analysis as well as for plant engineering. Some of these TFs could also be localized on the cacao reference map related to witches' broom resistance, facilitating the breeding and selection of resistant cacao trees.

Key words: Macroarrays; RT-qPCR; Gene regulation; Theobroma cacao; Witches' broom disease

\section{INTRODUCTION}

Plant diseases caused by pathogens are a major threat to agriculture production worldwide. Cacao (Theobroma cacao L.) is one of the most important tropical crops but its production is threatened by numerous pathogens such as the hemibiotrophic fungus Moniliophthora perniciosa, which is responsible for witches' broom disease (Purdy and Schmidt, 1996). Witches' broom is one of the major cacao diseases in South America and the Caribbean Islands, destroying plantations and leading to important economic and social changes in areas of concern, such as the State of Bahia in Brazil (Andebrhan et al., 1999). Basidiospores infect meristematic tissues (shoots, flower cushions, single flowers, and developing fruits) and induce a range of symptoms depending on the organ infected and the developmental stage. Infection of apical meristems leads to hypertrophy and hyperplasia of the tissues, loss of apical dominance, and proliferation of axillary shoots, which results in the formation of abnormal stems called green brooms. In this biotrophic phase of the disease, the fungus is intercellular, whereas in the necrotrophic phase, the fungus becomes intracellular and causes necrosis and death of infected tissues distal from the original infection site, producing a dry broom (Ceita et al., 2007). Basidiocarp production and spore formation occur on infected necrotic tissue completing the infection cycle (Silva et al., 2002).

In order to understand the mechanisms that lead to the disease development in cacao, some molecular studies have been recently conducted, and the identification of candidate genes involved in cacao resistance to M. perniciosa initiated. In 2007, Leal et al. obtained two SSH libraries from shoot tips of susceptible (ICS 39) and resistant (CAB) cacao genotypes inoculated or not with $M$. perniciosa, and identified genes related to plant defense at different stages of the interaction. Gesteira et al. (2007) made two full-length cDNA libraries from susceptible (Catongo) and resistant (TSH1188) cacao genotypes challenged with M. perniciosa. A wide range of information generated from these different molecular studies on cacao offers an unprecedented opportunity to identify genes and regulatory networks that control the response of the defense of cacao to M. perniciosa, such as transcription factors (TFs) that act as master regulators of cellular processes and play critical roles in the regulation of gene expression during plant defense responses (Journot-Catalino et al., 2006). Members of several families of transcription factors such as bZIP, MYB, MYC, and WRKY have been able to bind to promoter elements of individual genes related to defense and regular expression (Jalali 
et al., 2006). The identification and characterization of TFs may highlight the initial steps of transduction pathway leading to cacao resistance (or susceptibility) to M. perniciosa.

In this study, we developed a macroarray with 88 cDNAs identified as TFs in the libraries obtained by Gesteira et al. (2007). Seventy-two TFs were found differentially expressed between the susceptible (Catongo) and resistant (TSH1188) genotypes and/or during the disease time course - from $24 \mathrm{~h}$ after infection (hai) to 30 days after infection (dai). Most of the TFs differentially expressed belong to bZIP, MYB and WRKY families and presented opposite expression patterns in susceptible and resistant cacao-M. perniciosa interactions (i.e., up-regulated in Catongo and down-regulated in TSH1188). The results of the macroarray were confirmed for bZIP and WRKY TFs by real-time polymerase chain reaction (PCR).

\section{MATERIAL AND METHODS}

\section{Plant material and fungus strain}

Plantlets of T. cacao L. varieties Catongo (susceptible to M. perniciosa) and TSH1188 (resistant to M. perniciosa) were grown in the greenhouse at CEPEC/CEPLAC (Centro de Pesquisas da Comissão Executiva do Plano da Lavoura Cacaueira, Itabuna, BA, Brazil) under natural light and $90 \%$ relative humidity. Apical meristems of 4 -week-old plantlets were inoculated by the spray method using a $10^{5} / \mathrm{mL}$ basidiospore suspension from the $M$. perniciosa strain Cp 1441 CEPEC/CEPLAC. After inoculation, plantlets were acclimated for $24 \mathrm{~h}$ at 25 $\pm 2^{\circ} \mathrm{C}$ in a water-saturated atmosphere to allow M. perniciosa spore germination, penetration and consequently infection (Frias et al., 1995). A test of spore viability was made in a humid chamber $\left(25^{\circ} \mathrm{C}\right) 24 \mathrm{~h}$ after inoculation and was compared with spore viability obtained before inoculation. Control plantlets were inoculated with sterile water and submitted to the same growing conditions as the inoculated ones. Expression of susceptibility was estimated 4 weeks after inoculation by detection of the Catongo plants with disease symptoms. Disease development was monitored on the growing plants for a period of 90 dai. Inoculated and noninoculated apical meristems from Catongo and TSH1188 were harvested at 24, 48 and 72 hai, and 15 and 30 dai. Infected and uninfected resistant and susceptible apical meristems were harvested, frozen in liquid nitrogen and stored at $-80^{\circ} \mathrm{C}$.

\section{Macroarray procedure}

A total of $88 \mathrm{cDNAs}$ were selected from two libraries providing, respectively, TSH1188 and Catongo challenged with M. perniciosa (Gesteira et al., 2007). For putative functional cDNA designation, sequences were compared with a public sequence database (http://www.ncbi.nlm. nih.gov) using BLASTX. The complete 88 inserts were amplified from the plasmid clones by PCR in a final volume of $50 \mu \mathrm{L}$ containing $100 \mathrm{ng}$ DNA, $0.2 \mu \mathrm{M}$ of each primer (pDNR-F 5'-ATCAGTCGACGGTACCGGAC-3'; pDNR-R 5'-ACAGCTATGACCATGTTCAC-3'), $1 \mathrm{X}$ buffer, $0.4 \mathrm{mM}$ dNTPs, $1 \mathrm{mM} \mathrm{MgCl}$, and $2 \mathrm{U}$ Taq DNA polymerase. A touchdown PCR was made under the following conditions: 5 min at $95^{\circ} \mathrm{C}$ followed by 10 cycles of $40 \mathrm{~s}$ at $94^{\circ} \mathrm{C}, 45 \mathrm{~s}$ at $65^{\circ} \mathrm{C}$ (decreasing of $0.2^{\circ} \mathrm{C}$ per cycle), $1 \mathrm{~min}$ and $20 \mathrm{~s}$ at $72^{\circ} \mathrm{C}$, followed by 30 cycles of $40 \mathrm{~s}$ at $94^{\circ} \mathrm{C}, 45 \mathrm{~s}$ at $62^{\circ} \mathrm{C}, 1 \mathrm{~min}$ and $20 \mathrm{~s}$ at $72^{\circ} \mathrm{C}$, and a final extension of $7 \mathrm{~min}$ at $72^{\circ} \mathrm{C}$ done in a Mastercycler Gradient (Eppendorf). Quality of PCR products was checked on 1\% agarose gel 
stained with ethidium bromide. The PCR products were organized on 96-well plates. To each well, $10 \mu \mathrm{L} 0.8 \mathrm{M} \mathrm{NaCl}$ was added and the plates were held at $37^{\circ} \mathrm{C}$ for $15 \mathrm{~min}$ to denature DNA. Plasmid DNAs were printed on Hybond $\mathrm{N}^{+}$Nylon membranes (Amersham Pharmacia Biotech) using a 96-well replicator and linked to the membrane at $80^{\circ} \mathrm{C}$ for $2 \mathrm{~h}$. Four replicates for each clone were spotted on each membrane.

\section{Total RNA isolation}

Total RNA was extracted from 24, 48, and 72 hai, and 15 and 30 dai samples (pools of three frozen meristems each) as described by Gesteira et al. (2003) with modifications according to Rodrigues et al. (2007), and then cleaned using the Rneasy Plant Mini kit as described by the manufacturer protocol (Qiagen). The RNA was treated with DNase (Fermentas), and the RNA purity and concentration were determined spectrophotometrically at $260 \mathrm{~nm}$ (Cary ${ }^{\mathbb{B}}$ 100 UV-Visible Spectrophotometer, Varian, Palo Alto, CA, USA). RNA was separated on 1\% DEPC-treated agarose gel and stained with ethidium bromide to confirm RNA integrity. For macroarray probe preparation, total RNA from 24,48 , and 72 hai samples were joined in a unique pool named Pool $72 \mathrm{~h}$ ).

\section{Macroarray probe preparation}

Because of the low amounts of RNA obtained from meristems, it was necessary to linearly amplify the RNA as described by Wang (2005). First-strand cDNAs were reverse transcribed from total RNA (about $200 \mathrm{ng}$ ) using $0.1875 \mu \mathrm{g} / \mu \mathrm{L}$ primer $\mathrm{dT}_{(15)}-\mathrm{T} 7$ (5'-AAACGACG GCCAGTGAATTGTAATACGACTCACTATAGGCGCT $\left._{(15)}-3^{\prime}\right), 0.1875 \mu \mathrm{g} / \mu \mathrm{L}$ primer TS (5'-AAGCAGTGGTAACAACGCAGAGTACGCGGG-3') and 200 U RevertAid ${ }^{\text {TM }}$ MMuLV Reverse Transcriptase as described by the manufacturer instruction (Fermentas). To prevent RNA degradation during reverse transcription, 2 U RNase Out (Invitrogen) was used. Second-strand cDNA was obtained using 1 X Advantage PCR Buffer, 0.8 M dNTPs, 1 U RNase $\mathrm{H}$ and $3 \mu \mathrm{L}$ Advantage cDNA Polymerase Mix in a final volume of $200 \mu \mathrm{L}$, as described by the manufacturer instruction (Clontech). Double-strand cDNA was purified by adding $0.1 \mu \mathrm{g}$ linear acrylamide (Ambion) and phenol-chloroform-isoamyl alcohol (25:24:1) to the reaction, and then transferred to Phase Lock Gel tubes (Eppendorf). The in vitro transcription was made using a RiboMAX Large Scale RNA Production System-T7 as described by the manufacturer instruction (Promega). The complementary RNA (cRNA) was cleaned with TRIzol ${ }^{\mathbb{}}$ reagent (Invitrogen) and chloroform. Final cDNA synthesis from cRNA was obtained by reverse transcription using $2 \mu \mathrm{g} / \mu \mathrm{L}$ random hexamer primer (dN6) and the RevertAid ${ }^{\mathrm{TM}} \mathrm{M}-\mathrm{MuLV}$ Reverse Transcriptase, as described by the manufacturer instruction (Fermentas). cDNA quantification was realized on a GeneQuant Pro spectrophotometer (Biochrom). Concentrations of the cDNA from different plant samples were comprised between 1.1 and $1.5 \mu \mathrm{g} / \mu \mathrm{L}$.

\section{Hybridization conditions, data management and statistical analyses}

The cDNA spotted on nylon membranes were hybridized with the cDNA probes labeled according to manufacturer instructions (Alkphos Direct ${ }^{\mathrm{TM}}$ Labelling kit, GE Healtcare) and following the procedure described by Li et al. (2006). Hybridization signals were detected 
using CDP-star chemiluminescence (Amersham Pharmacia Biotech). The arrays were exposed to ECL Hyperfilm ${ }^{\mathrm{TM}}$ (Amersham Biosciences) for $2 \mathrm{~h}$. The target signal intensities were scanned on a Kodak EDAS 290 imaging system. Quantification of signal intensity representing hybridized cDNA was performed using the BZScan program (Lopez et al., 2004). Each spot was first defined by automatic grid positioning over the array image, and then a manual checking and correction of positioning for each spot were performed. Intensity values were calculated by the Quant Fit Calculated algorithm, which: i) subtracts the local background for each spot and ii) determines qualitatively the non-confident spots (quality metric). The normalization was made by the global method as described by Yang et al. (2002) comparing each inoculated time with the control (non-inoculated one) for each genotype: a factor $c$, calculated separately using the intensity average of all the spots, was subtracted from the raw values. The genes were determined as differentially expressed if the fold change was greater than 2 or below -2. In order to identify temporal patterns of expression within the M. perniciosaresponsive transcripts, we subjected the filtered, normalized macroarray data points to Cluster package analysis (Eisen et al., 1998), which classifies the data into groups based on temporal expression patterns. Fold changes were supplied to complete hierarchical clustering algorithm and graphic results of clustering were visualized by the TreeView program.

\section{Real-time quantitative PCR analyses}

For real-time quantitative PCR (RT-qPCR), the cDNA was obtained by reverse transcription from total RNA using $0.5 \mu \mathrm{g} / \mu \mathrm{L}$ oligo(dT) ${ }_{18}$ primer and the RevertAid ${ }^{\mathrm{TM}} \mathrm{M}-\mathrm{MuLV}$ Reverse Transcriptase as described by the manufacturer instruction (Fermentas). RT-qPCR analyses were used to follow the expression pattern of a selected number of genes at early stage of infection: two bZIP (RT42C09 and RT57A09) and one WRKY TFs (RT43H02). The $\beta$-tubulin gene (RT001C02), which did not show significant differential expression on the macroarray, was used as endogen for the RT-qPCR experiment. Specific primers were designed for each gene: RT42C09-F 5'-GCCCGATATAAGGGATGCTTT-3' and RT42C09R5'-CAACAATGGCCATGTCATCATT-3' (amplified product of $100 \mathrm{bp}, \mathrm{Tm}=80^{\circ} \mathrm{C}$ ) for bZIP-RT42C09; RT57A09-F 5'-GGCCAAATTGAATGGGTTAAAG-3' and RT57A09-R 5'-CTTGAATGCAAACAATGGCAGTA-3' (amplified product of $100 \mathrm{bp}, \mathrm{Tm}=77^{\circ} \mathrm{C}$ ) for bZIP-RT57A09; RT43H02-F 5'-AACATAACCACGAGATGCCACTT-3' and RT43H02R 5'-TTCAGTTGCTATCATCGCTTGTC-3' (amplified product of $100 \mathrm{bp}, \mathrm{Tm}=78^{\circ} \mathrm{C}$ ) for WRKY-RT43H02, and tubulin-F 5'-TGCAACCATGAGTGGTGTCA-3' and tubulin-R 5'-CTGGTCTCAGCAGCCAAAATG-3' for the endogen (amplified product of $193 \mathrm{bp}, \mathrm{Tm}$ $=85^{\circ} \mathrm{C}$ ). The RT-qPCR analysis was made using SYBRGreen ${ }^{\circledR}$ (Invitrogen) for fluorescence detection during amplification. Assays were performed on an ABI PRISM 7500 Sequence Detection System (SDS) coupled to an ABI PRISM 7500 SDS software (Applied Biosystems) using standard settings. The 20- $\mu$ L RT-PCR consisted of SYBR Green 1X (Applied Biosciences), PCR buffer 1X, $0.1 \mathrm{mM}$ dNTPs, $1.5 \mathrm{mM} \mathrm{MgCl}$, Rox $0.0625 \mathrm{X}$ (Invitrogen), 0.2 pmol of each primer, $0.5 \mathrm{U}$ Taq platinium (Invitrogen) and $100 \mathrm{ng}$ single-stranded cDNA. The thermal cycling conditions were $94^{\circ} \mathrm{C}$ for $10 \mathrm{~min}$, followed by 45 cycles of $94^{\circ} \mathrm{C}$ for $15 \mathrm{~s}$ and $60^{\circ} \mathrm{C}$ for $45 \mathrm{~s}$. A dissociation analysis was conducted after each amplification to investigate primer dimer and hairpin formation. Melting temperature of the fragments was determined according to the manufacturer protocol (Applied Biosystems). No-template reactions were used 
as negative controls. The results obtained with the Sequence Detection Software (Applied Biosystems) were transferred to Microsoft Excel for further analysis. Raw expression levels were calculated from the average of the triplicate ddCT (RQ) values. Non-inoculated plants (control) were used as a calibrator for both varieties and the experiment was conducted with three biological replicates, each one formed by a pool of three meristems. The BioEstat 5.0 program was used for statistical analyses.

\section{RESULTS}

\section{Macroarray analyses}

The expression analysis of cacao TFs possibly involved in plant response to M. perniciosa infection was performed by macroarray containing cDNAs identified on T. cacao-M. perniciosa interaction libraries (Gesteira et al., 2007). The macroarray was formed by $88 \mathrm{TF}$ cDNAs, two constitutive cDNAs ( $\alpha$ - and $\beta$-tubulin) and one negative control ( $\lambda$ DNA). The TF cDNA list is divided into 24 zinc finger proteins, 6 bZIP, 5 WD-40, 8 MYB, 5 bHLH, 3 WRKY, and 37 sequences belonging to other TF families. The cDNA length varied between 123 and $808 \mathrm{bp}$ with an average of $386 \mathrm{bp}$ (Supplementary material). The macroarrays were hybridized with probes from non-inoculated plants (control) or inoculated plants harvested at 24, 48 and 72 hai (joined in an unique cDNA pool named Pool $72 \mathrm{~h}$ ) and at 15 and 30 dai on both resistant (TSH1188) and susceptible (Catongo) varieties. The differentially expressed genes were listed in Table 1.

From the 88 TF cDNAs analyzed, 72 showed a differential expression pattern. Sixty TF cDNAs were differentially expressed in Catongo: 18 were up-regulated, 41 down-regulated, and only one was up- and down-regulated through the disease time course (clone RT42C09; Table 1). Among the up-regulated TFs, only one was induced in the early hours (Pool $72 \mathrm{~h}$ ), 3 at 15 dai, 7 in both Pool $72 \mathrm{~h}$ and 15 dai, and 7 in both 15 and 30 dai (Figure 1A). Among down-regulated TFs, one was repressed at Pool $72 \mathrm{~h}, 7$ were repressed in both Pool $72 \mathrm{~h}$ and 15 dai, 20 at 15 dai, 5 at 30 dai, 5 in both 15 and 30 dai, and 3 in both Pool $72 \mathrm{~h}$ and 30 dai (Figure 1B).

In the susceptible variety, most of the TF family members potentially related to defense response of cacao to M. perniciosa infection were repressed from 24 hai to 30 dai (Figure 2). By analyzing all the significantly expressed genes in Catongo, four different regulatory patterns were observed in the hierarchical clustering (Figure 2). Cluster I corresponded to TFs with high expression at Pool $72 \mathrm{~h}$ followed by a decreasing expression at 15 and 30 dai (Figure 2B). This group included three MYB and one gene similar to CCR4-NOT transcription complex, which is known to be involved in plant defense (Sarowar et al., 2007; Table 1). Cluster II contained TFs repressed in control and at Pool $72 \mathrm{~h}$ followed by an increase of expression at 15 and 30 dai (Figure 2C). In this group, zinc finger proteins and TFs of the bHLH family were found (Table 1). Cluster III contained TFs slightly down-regulated at Pool $72 \mathrm{~h}$ and 15 dai, and then slightly up-regulated at 30 dai (Figure 2D). This cluster contained the largest number of TFs including the WRKY, bZIP, MYB, and zinc finger protein families considered as the main TF families regulating plant defense responses (Table 1). In cluster IV, TFs were slightly up-regulated in control then a decrease of expression intensity at Pool $72 \mathrm{~h}$, an up-regulation of the genes at 15 dai, and finally a repression of the expression at 30 dai was observed (Figure 2E). 
Transcription factors expressed in witches' broom disease

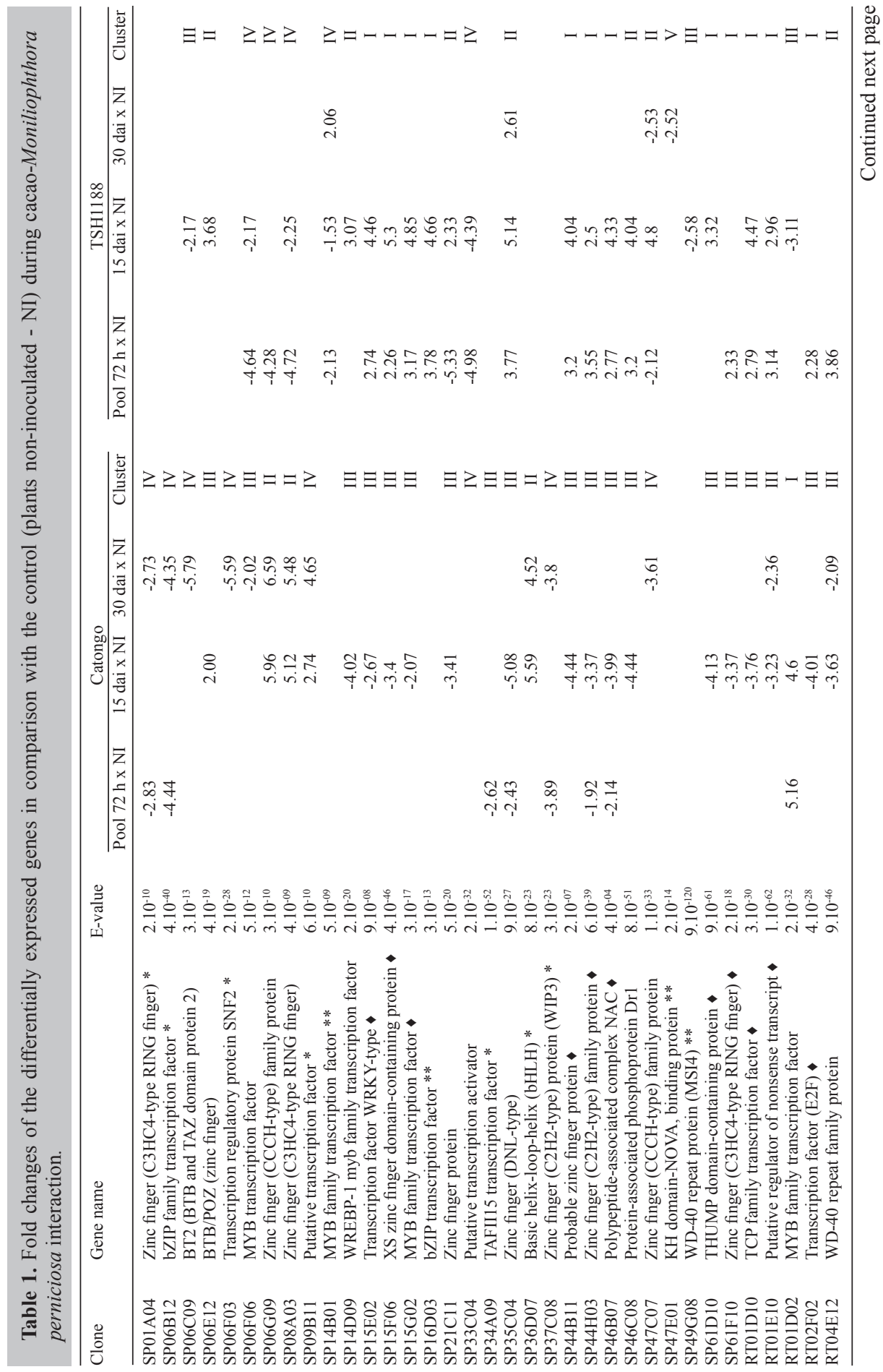

Genetics and Molecular Research 9 (3): 1279-1297 (2010)

CFUNPEC-RP www.funpecrp.com.br 
M.A. Lopes et al.

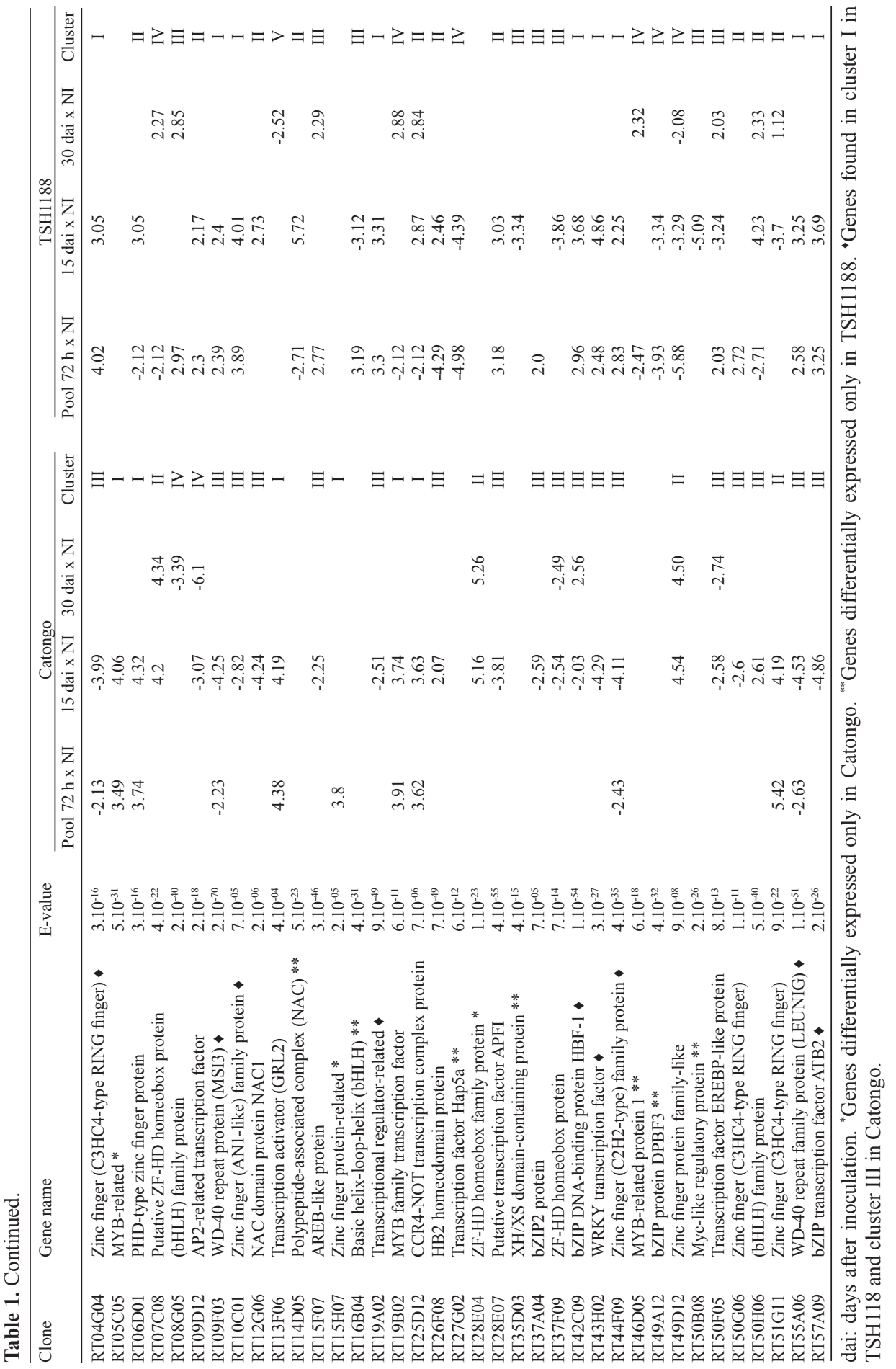

Genetics and Molecular Research 9 (3): 1279-1297 (2010)

CFUNPEC-RP www.funpecrp.com.br 

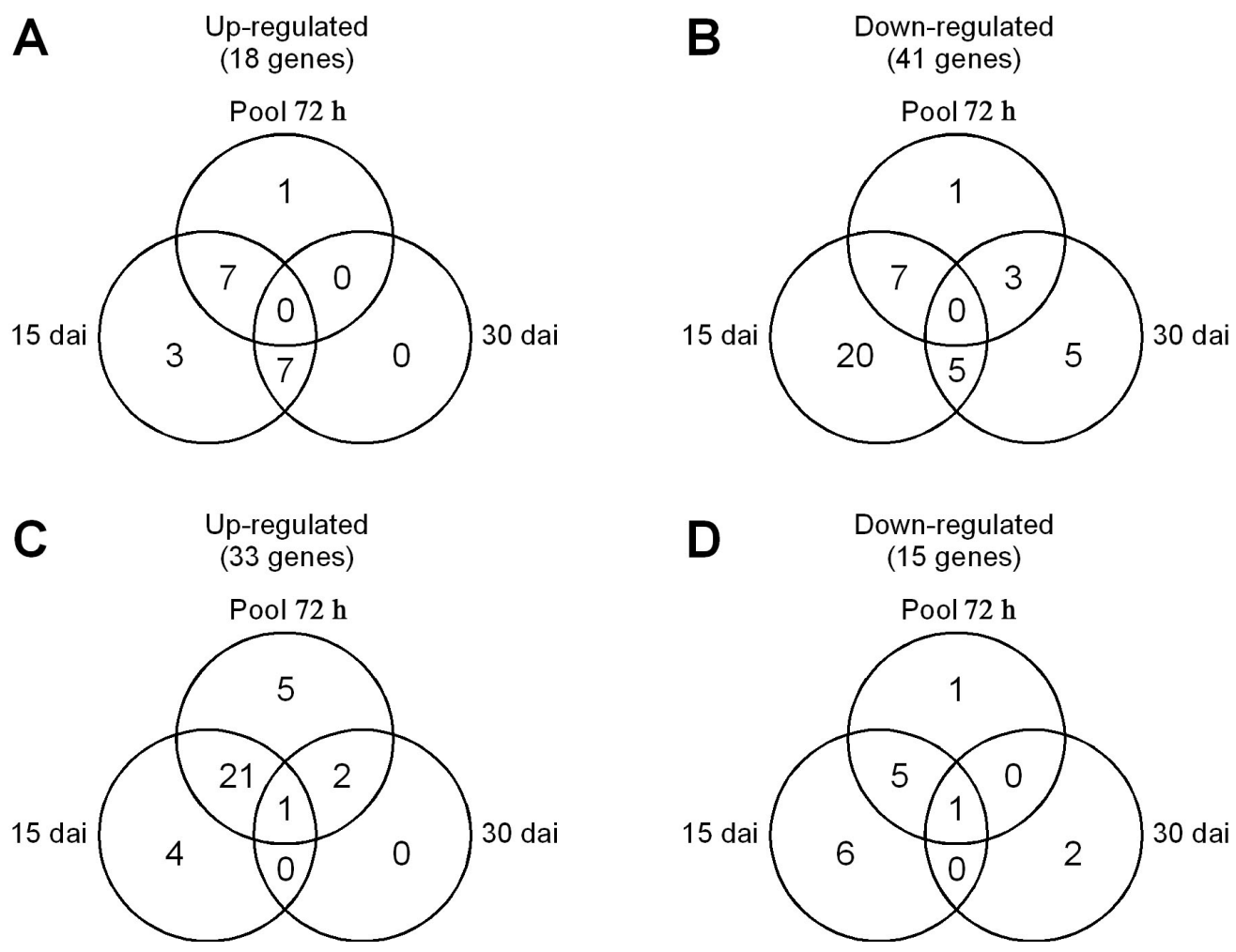

Figure 1. Venn diagram showing the distribution of the differentially expressed transcription factors of cacao challenged with Moniliophthora perniciosa between three measurement times after inoculation (Pool $72 \mathrm{~h}$, and 15 and 30 days after infection, dai). A. Genes up-regulated in Catongo. B. Genes down-regulated in Catongo. C. Genes up-regulated in TSH1188. D. Genes down-regulated in TSH1188.

In TSH1188, 62 of the 88 TFs displayed change in the transcript level (Table 1): 33 were induced, 15 were repressed and 14 were up- and down-regulated through the disease time course. Among the up-regulated TFs, 5 were induced at Pool 72 h, 4 at 15 dai, 21 in both Pool $72 \mathrm{~h}$ and 15 dai, 2 in both Pool $72 \mathrm{~h}$ and 30 dai, and 1 common to all the harvesting times (Figure 1C). Among the down-regulated TFs, only one was repressed at Pool 72 h, 6 at 15 dai, 2 at 30 dai, 5 in both Pool $72 \mathrm{~h}$ and 15 dai, and 1 common to all the harvesting times (Figure 1D). In TSH1188, unlike Catongo, various members of TF families important to defense responses were up-regulated in the early hours after the infection by M. perniciosa. Five regulatory patterns of expression were observed in TSH1188 (Figure 3A). TFs with an increase of expression at Pool $72 \mathrm{~h}$ and 15 dai, followed by a decrease of expression at 30 dai (with the same intensity than control) were grouped in cluster I (Figure 3B). This cluster contained 21 TFs including WRKY, bZIPs, zinc finger proteins, and other TF families (Table 1). Cluster II contained 17 TFs with high repression at Pool $72 \mathrm{~h}$, high up-regulation at 15 dai, followed by a slight expression decrease at 30 dai (Figure 3C). In this cluster, we found zinc finger proteins, WD-40, bHLH, and CCR4-NOT TFs (Table 1). In cluster III, we observed TFs with a downregulation at 15 dai (Figure 3D). In cluster IV, TFs were highly expressed in control and at 

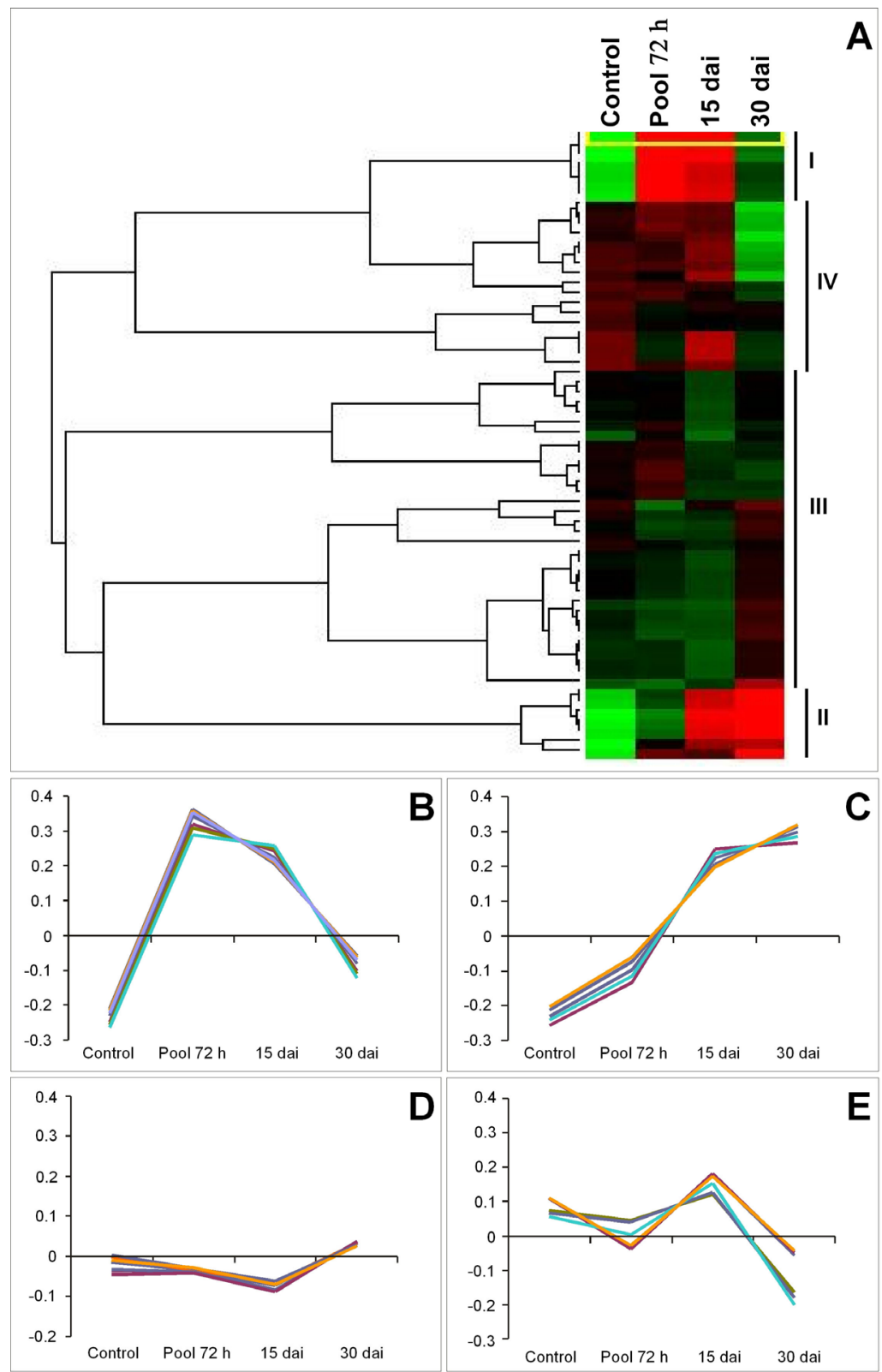

Figure 2. Hierarchical clustering illustrating groups of Catongo genes co-ordinately expressed in response to Moniliophthora perniciosa infection at Pool $72 \mathrm{~h}$, and 15 and 30 days after infection (dai). A. Hierarchical clustering of 60 genes differentially expressed in Catongo variety. Each column corresponds to a measurement time (Pool 72 h, 15 or 30 dai) and each row corresponds to one gene. For each gene, the fold change of mRNA level in inoculated versus the corresponding control tissues is represented by red or green, indicating up-regulation or down-regulation, respectively. The differentially expressed genes were classified into four regulatory patterns (clusters), indicated by numbers I through IV. B. to E. Graphical representations of the four regulatory patterns. The y-axis represents spot intensity in logarithm value. 
30 dai, and strongly repressed at Pool $72 \mathrm{~h}$ and 15 dai (Figure 3E). Finally, cluster V, containing only two genes, corresponded to TFs with high expression in control and at Pool $72 \mathrm{~h}$, and repression of gene expression at 15 and 30 dai (Figure $3 F$ ).
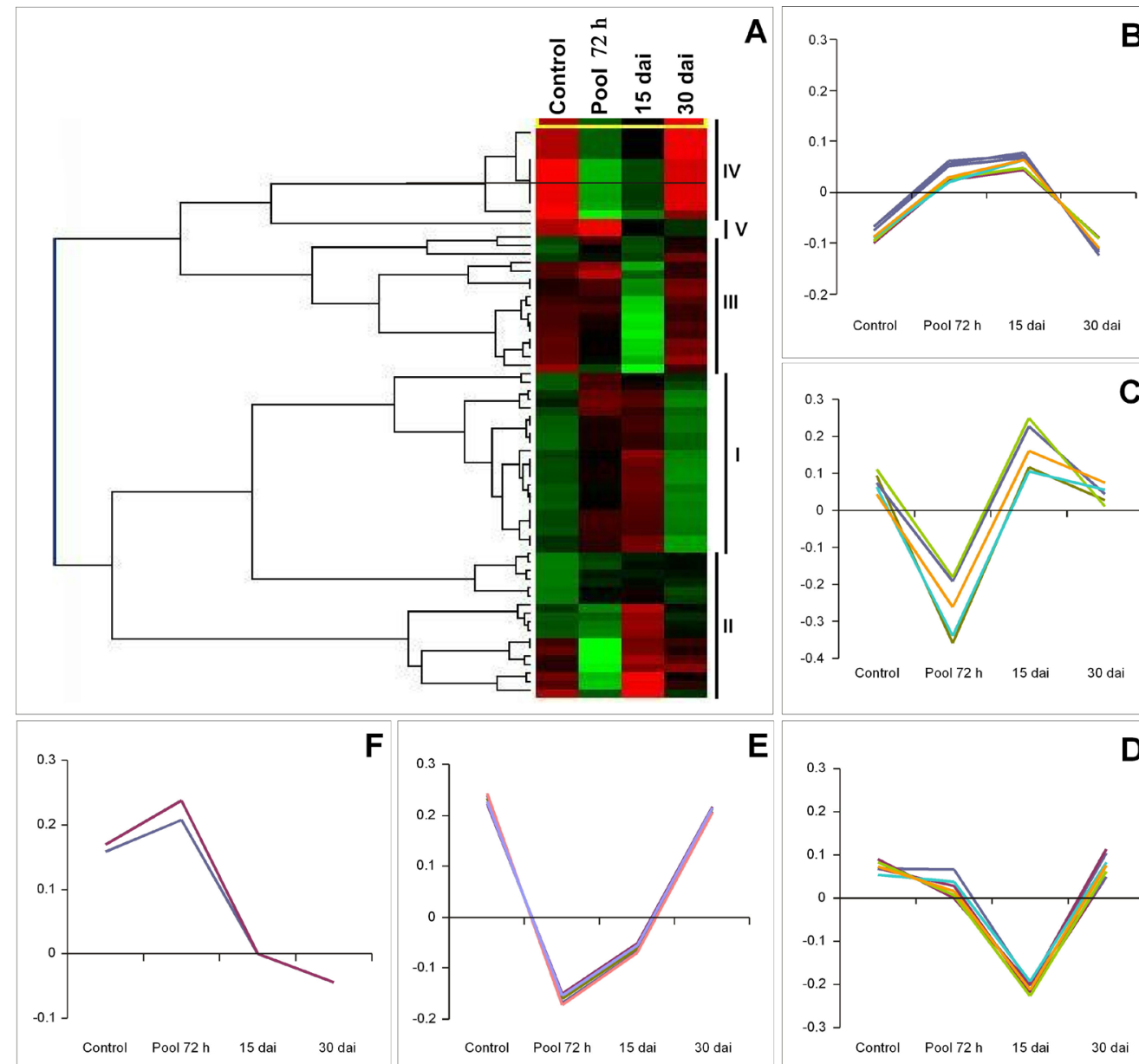

$\mathbf{E}$
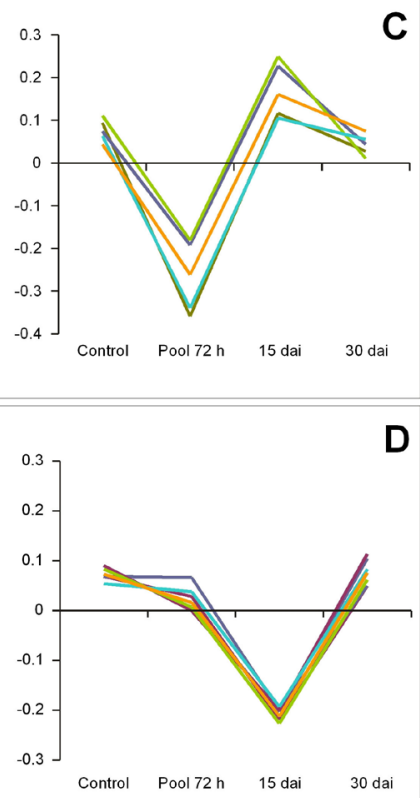

Figure 3. Hierarchical clustering illustrating groups of TSH1188 genes co-ordinately expressed in response to Moniliophthora perniciosa infection at Pool $72 \mathrm{~h}$, and 15 and 30 days after infection (dai). A. Hierarchical clustering of 62 genes differentially expressed in TSH1188. Each column corresponds to a measurement time (Pool $72 \mathrm{~h}, 15$ or 30 dai) and each row corresponds to one gene. For each gene, the fold change of mRNA level in inoculated versus the corresponding control tissues is represented by red or green, indicating up-regulation or down-regulation, respectively. The differentially expressed genes were classified into five regulatory patterns (clusters), indicated by numbers I through V. B. to F. Graphical representations of the five regulatory patterns. The y-axis represents spot intensity in logarithm value.

Among the 88 TFs, 10 showed a differential expression only in Catongo (Table 1; 1 asterik) while 11 were differentially expressed only in TSH1188 (Table 1; 2 asteriks). Among the 18 TFs up-regulated in Catongo, 5 were differentially expressed only in Catongo, one was up-regulated in both varieties, 7 were both repressed and induced, and 5 were down-regulated 
in TSH1188. Conversely, from the 41 TFs down-regulated in Catongo, 5 were differentially expressed only in Catongo, 3 were down-regulated in both varieties, 2 were repressed and induced, and 31 were up-regulated in TSH1188. Among the TFs down-regulated in Catongo and up-regulated in TSH1188, some members of the main TF families in plant defense regulation seemed more interesting, such as MYB, zinc finger proteins and especially bZIP and WRKY, which can act together in plant defense signaling (Eulgem, 2005; Jalali et al., 2006).

\section{Real-time PCR}

Expression analysis by RT-qPCR was made on 24, 48 and 72 hai, and 15 dai samples in Catongo and TSH1188 for two bZIP and one WRKY TF (RT42C09, RT57A09 and RT43H02, respectively; Figure 4). On macroarrays, these TFs are grouped in cluster III in Catongo (showing down-regulation at 15 dai) and in cluster I in TSH1188 (showing upregulation at Pool $72 \mathrm{~h}$ and 15 dai, with quite similar expression intensity in this two harvesting times) (Table 1, Figures 2 and 3). The RT-qPCR data showed that globally, for the three genes analyzed, the expression intensity is higher in TSH1188 than in Catongo (Figure 4). In TSH1188, for the bZIP-RT42C09, similar expression intensities were observed in the early hours of interaction $(0.93,0.88,0.81$ for 24,48 and $72 \mathrm{~h}$, respectively) while the expression increased at 15 dai (2.58 with a statistically significant difference in relation to the early hours of interaction). In Catongo, the highest intensity was observed at 48 hai (0.87), and the lowest expression intensity was observed at 15 dai (0.19) (Figure 4A). For bZIP-RT57A09, in TSH1188, the intensities were relatively high (1.19 at 15 dai to 2.8 at 24 hai) but no significant difference was observed between the four samples analyzed. In Catongo, no expression was detected at 24 hai, and similar intensities were observed at 48 hai, 72 hai and 15 dai $(0.37$, 0.38 and 0.55 , respectively, without significant statistical differences) (Figure 4B). For the WRKY-RT43H02 gene, in TSH1188, the same intensity was observed between 24 hai (1.4) and 72 hai (1.4). However, a significant intensity difference was observed between 48 hai and 15 dai samples ( 0.92 and 1.67, respectively). In Catongo, the highest intensity was observed at 48 hai and 72 hai (0.45), and the lowest expression intensity was observed at 15 dai (0.08) (Figure 4C).

\section{DISCUSSION}

Global gene expression studies have become a highly valuable source for functional genomics. In particular, arrays- and qPCR-based studies have identified several TF types, such as WRKY, bZIP and MYB factors in different plant species (Eulgem, 2005; Jalali et al., 2006; Yang et al., 2009). Such TFs are known to participate in defense regulation processes in plants: to defeat pathogens, the plant has to regulate TFs in a timely manner after recognizing the pathogen in order to activate a flood of defense-related genes (Eulgem, 2005; Jalali et al., 2006). To understand the role of TFs in cacao, the present study aimed to identify defenserelated TF genes whose expression is differentially regulated in cacao plants infected versus uninfected by M. perniciosa. Eighty-eight TF genes were selected from cacao-M. perniciosa interaction cDNA libraries (Gesteira et al., 2007); among them TFs belonging to bZIP, zinc finger proteins, MYB, and WRKY families were identified. In tobacco, TGA factors, which belong to a sub-family of bZIP TFs, have a major importance in salicylic acid (SA)-inducible 

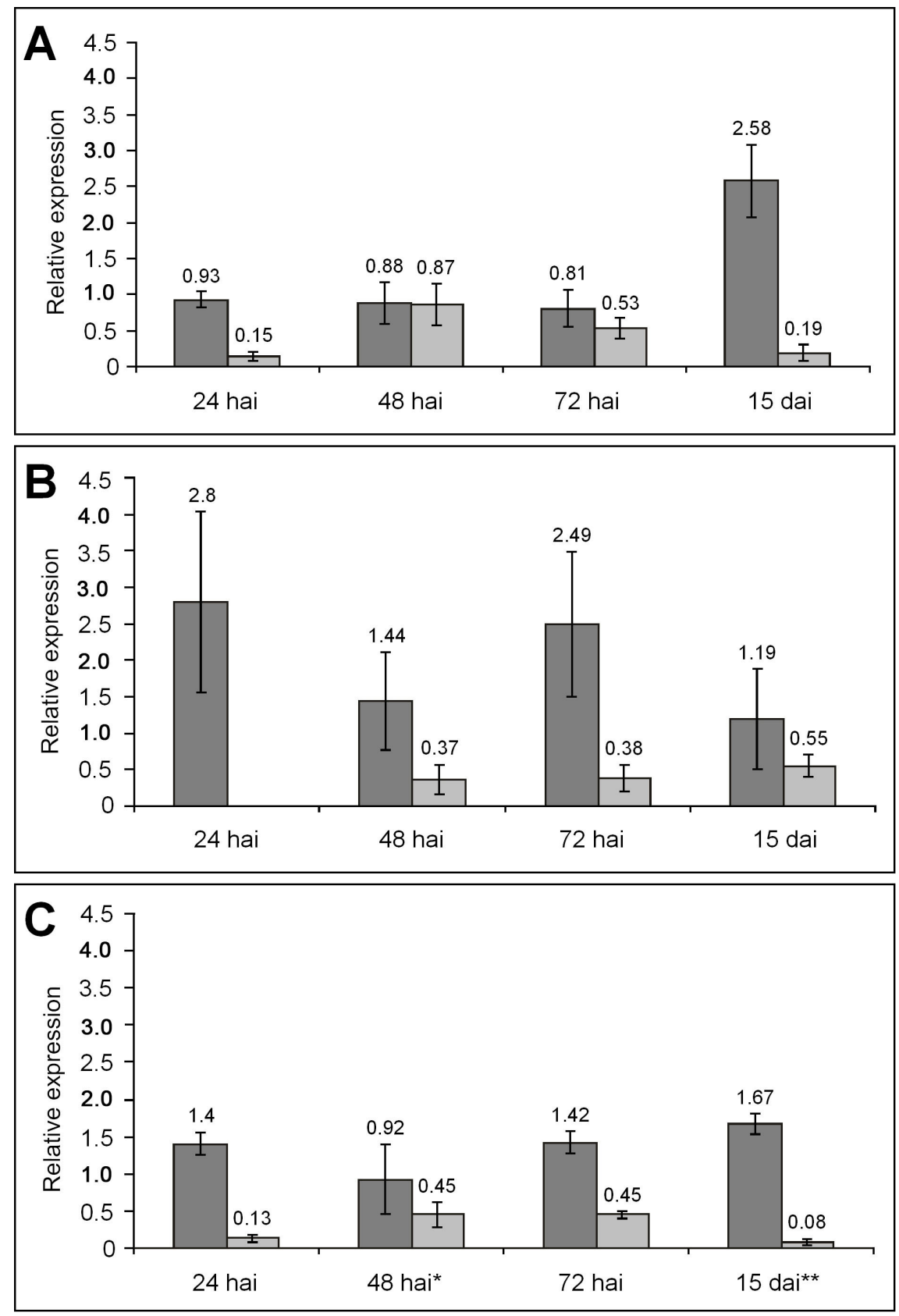

Figure 4. Expression of two different bZIP and one WRKY transcription factors by RT-qPCR in Catongo and TSH1188 cacao varieties. A. Relative expression level of bZIP-RT42C09. B. Relative expression level of bZIPRT57A09. C. Relative expression level of WRKY-RT43H02. *Times analyzed only with two biological replicates in TSH1188. **Times analyzed only with two biological replicates in Catongo. Expression in TSH1188 and Catongo is shown in dark and light gray, respectively. hai = hours after infection; dai = days after infection. 
gene expression (Thurow et al., 2005), while in Arabidopsis they play a role up-regulating the plant's systemic acquired resistance (SAR) (Eulgem, 2005). The bZIP TFs also have role in modulation of basal defense and cell death following infection by a pathogen: in Arabidopsis, the bZIP10 gene is induced by reactive oxygen species inducing the hypersensitive response (HR) (Kaminaka et al., 2006). In Arabidopsis, several genes encoding MYB TFs are up-regulated after infection by pathogen, and act as a positive regulator of the HR (Raffaele et al., 2006). The MYB factors can bind to promoters of a variety of defense-associated genes but also to promoters of WRKY TFs (Dong et al., 2003; Eulgem, 2005). The WRKY proteins seem to play a greater transcriptional reprogramming role during a variety of immune responses. Functional studies involving loss and gain of function in Arabidopsis have shown that WRKY factors can act as both positive and negative regulators in the complex network of plant defense responses (Eulgem and Somssich, 2007). WRKY proteins bind to W-box elements present in promoters of several plant defense-related genes (Eulgem, 2005). These TFs appeared to be involved in regulation of basal defense and SAR, acting in regulation of the SA biosynthesis, and in regulation of the expression of NPR1, a central regulator of SA- and SAR-dependent defenses (Pandey and Somssich, 2009).

The cacao-M. perniciosa interaction TF macroarrays we developed here showed differential quantitative and qualitative gene expression between resistant and susceptible interactions and during the disease time course. The number of TFs induced in response to $M$. perniciosa was higher in the resistant cacao-M. perniciosa interaction (TSH1188) than in the susceptible one (Catongo): while 33 TFs were up-regulated in TSH1188 only 18 TFs were up-regulated in Catongo. Among the 33 TFs up-regulated in TSH1188, 21 were induced in the first 72 hai, while only seven of the 18 TFs up-regulated in Catongo were induced in the early hours of the infection. Among the TFs that present significant expression pattern differences between TSH1188 and Catongo were encountered members of the three large TF families involved in plant defense responses: MYB, bZIP and WRKY. It has been shown that MYB TFs are up-regulated in both varieties in the early hai: three and one MYB TFs were induced in Catongo and in TSH1188, respectively. In Arabidopsis, AtMYB30 acted as a positive regulator of the HR and was induced in response to bacteria pathogens (Raffaele et al., 2006). In perennial crops, the possible involvement of MYB factors in defense was also reported. In grapevine and poplar, they were involved in the regulation of the proanthocyanidin (PA) biosynthesis, a derivative of flavonoids that contributes to plant defense mechanisms against biotic and abiotic stress (Mellway et al., 2009; Terrier et al., 2009). In poplar, the MYB134 gene was induced by pathogen attack and abiotic stress, and transgenic poplar expressing constitutively MYB134 showed dramatic increase in PA concentration (Mellway et al., 2009). In addition, MYB TFs and PA biosynthesis genes are induced after infection by pathogens (Mellway et al., 2009). In our study, two of the three WRKY TFs were induced in TSH1188 in the early hai and repressed in Catongo at 15 dai. The role of WRKY TFs in the transcriptional reprogramming of plant defense responses, shown in studies using plant models, was also confirmed in perennial plants. In Coffea arabica, CaWRKY1 was induced in both compatible and incompatible interactions after $12 \mathrm{~h}$ of inoculation with Hemileia vastatrix, but the level of expression was higher in the incompatible interaction (Ganesh et al., 2006). The over-expression of grapevine $V v W R K Y 1$ in tobacco led to reduced susceptibility to both necrotrophic and biotrophic fungus (Marchive et al., 2007), whereas the constitutive expression of grapevine VvWRKY2 in tobacco plants reduced the susceptibility to Botrytis cinerea, Pytium spp and Alternaria tenius 
(Mzid et al., 2007). In cacao, previous expression studies showed changes in expression level of the WRKY family member TcWRKY1 during leaf development, after treatment with Nep1 and Phytophthora, and in response to mechanical wounding and defense inducers (Bailey et al., 2005a,b). In 2004, Borrone et al. isolated 16 cacao WRKY genes using degenerated primers. Four of these $(T c W R K Y 3,-10,-11,-14)$ were successfully converted into molecular markers and used for mapping (Borrone et al., 2004). These markers were used in an assisted selection program and mapping of quantitative trait locus for resistance to frosty pod and black pod diseases (Brown et al., 2007; Schnell et al., 2007). In the present study, we identified 3 WRKY TFs, one of which, RT43H02, is homolog to TcWRKY13 identified by Borrone et al. (2004) (data not shown). Because of the shortness of the sequences, it has not been possible to identify the homolog for the 2 other clones (SP15E02 and SP35E08). Further analysis of these three WRKY clones may allow their complete identification and correlation with WRKY clones already mapped (Borrone et al., 2004). Moreover, sequence analysis may allow marker identification and mapping on cacao population segregating for witches' broom disease (e.g., Sca6 x ICS1).

In the present study, MYB, bZIP and WRKY factors belonged to Catongo cluster III (TFs down-regulated at Pool $72 \mathrm{~h}$ and 15 dai, and then highly expressed at 30 dai) and to cluster I in TSH1188 (TFs with high expression intensity at Pool $72 \mathrm{~h}$ and 15 dai, followed by a slight decrease in intensity at 30 dai). Because they belonged to the same clusters both in resistant and susceptible interactions, it may be suggested that these TFs were co-regulated. In the literature, it has been described that WRKY, TGA and NPR1 TFs act coordinately for expression activation of PR1, a well-characterized marker of defense-response (Eulgem, 2005). WRKY and MYB factors are involved in regulation of the N-mediate resistance of the Nicotiana tabacum to tobacco mosaic virus (Liu et al., 2004), and in grapevine these factors are possibly involved in the regulation of the expression of the type I lipid transfer proteins (VvLTP1) involved in plant defense (Laquitaine et al., 2006). Thus, in cacao, it may be suggested that different TF families may be coordinately involved in defense response pathways against $M$. perniciosa.

For two TFs of the bZIP group (RT42C09 and RT57A09), we developed RT-qPCR experiments. The RT-qPCR results were correlated with the macroarray results, confirming them. Globally, these three genes were less expressed in Catongo than in TSH1188, which may be related to the down-regulation in Catongo observed on the macroarrays. It was also observed that the genes from cacao-M. perniciosa-resistant library (TSH1188/RT library; Gesteira et al., 2007) were more expressed in the TSH1188 tissues than in the Catongo ones, as expected. In TSH1188, the bZIP-RT42C09 expression was higher at 15 dai as observed in macroarray analysis (2.96 at Pool $72 \mathrm{~h}$ and 3.68 at 15 dai; Table 1). The WRKY-RT43H02 presented a relatively constant expression in TSH1188, as also observed on macroarrays $(3.25$ at Pool $72 \mathrm{~h}$ and 3.69 at 15 dai; Table 1). Only a few discrepancies were found between the two approaches: for the bZIP-RT57A09 clone in TSH1188, no difference of expression was observed between the 4 studied samples by RT-qPCR while on macroarrays the expression was higher at 15 dai. This can be explained by the level of sensitivity of the two methodological approaches: for the RT-qPCR experiment, primers and specific conditions of high stringency were used while in the macroarray experiment the stringency may be influenced by many more parameters. However, the use of a thematic macroarrays containing only TFs, which are generally lowly expressed, is more efficient than the use of arrays containing all kind of genes with a high expression level variability and containing highly expressed genes. 
In this study, we observed differences in cacao TF expression profile between susceptible and resistant interactions and during disease time course. Because TFs act as main regulators of the cellular process, the TFs with differential expression identified here may be considered as good candidates for subsequent functional analysis as well as for plant engineering, in order to allow a better understanding of the signaling pathways that trigger the resistance and/or susceptibility processes in cacao in response to M. perniciosa (Gurr and Rushton, 2005a,b; Century et al., 2008). Some of these TFs can also be localized on the cacao reference map related to witches' broom disease resistance, helping breeding programs and resistant cacao tree selection.

\section{ACKNOWLEDGMENTS}

M.A. Lopes, C.V. Dias and G.C. Santos were supported by Fundação de Amparo à Pesquisa do Estado da Bahia (FAPESB). B.T. Hora Júnior was supported by Coordenação de Aperfeiçoamento de Pessoal de Nível Superior (CAPES). Research supported by FAPESB, Conselho Nacional de Desenvolvimento Científico e Tecnológico (CNPq) and the International Foundation for Science (IFS). We thank Claudia Fortes Ferreira (Embrapa) for critical reading the manuscript.

\section{REFERENCES}

Andebrhan T, Figueira A, Yamada MM, Cascardo J, et al. (1999). Molecular fingerprinting suggests two primary outbreaks of witches' broom disease (Crinipellis perniciosa) of Theobroma cacao in Bahia, Brazil. Eur. J. Plant Pathol. 105: $167-175$.

Bailey BA, Bae H, Strem MD, Antunez de MG, et al. (2005a). Developmental expression of stress response genes in Theobroma cacao leaves and their response to Nep1 treatment and a compatible infection by Phytophthora megakarya. Plant Physiol. Biochem. 43: 611-622.

Bailey BA, Strema MD, Bae H, Mayolo GA, et al. (2005b). Gene expression in leaves of Theobroma cacao in response to mechanical wounding, ethylene, and/or methyl jasmonate. Plant Sci. 168: 1247-1258.

Borrone JW, Kuhn DN and Schnell RJ (2004). Isolation, characterization, and development of WRKY genes as useful genetic markers in Theobroma cacao. Theor. Appl. Genet. 109: 495-507.

Brown JS, Phillips-Mora W, Power EJ, Krol C, et al. (2007). Mapping QTLs for resistance to frosty pod and black pod diseases and horticultural traits in Theobroma cacao L. Crop Sci. 47: 1851-1858.

Ceita GO, Macêdo JNA, Santos TB, Alemanno L, et al. (2007). Involvement of calcium oxalate degradation during programmed cell death in Theobroma cacao tissues triggered by the hemibiotrophic fungus Moniliophthora perniciosa. Plant Sci. 173: 106-117.

Century K, Reuber TL and Ratcliffe OJ (2008). Regulating the regulators: the future prospects for transcription-factorbased agricultural biotechnology products. Plant Physiol. 147: 20-29.

Dong J, Chen C and Chen Z (2003). Expression profiles of the Arabidopsis WRKY gene superfamily during plant defense response. Plant Mol. Biol. 51: 21-37.

Eisen MB, Spellman PT, Brown PO and Botstein D (1998). Cluster analysis and display of genome-wide expression patterns. Proc. Natl. Acad. Sci U. S. A. 95: 14863-14868.

Eulgem T (2005). Regulation of the Arabidopsis defense transcriptome. Trends Plant Sci. 10: 71-78.

Eulgem T and Somssich IE (2007). Networks of WRKY transcription factors in defense signaling. Curr. Opin. Plant Biol. 10: 366-371.

Frias GA, Purdy LH and Schmidt RA (1995). An inoculation method for evaluating resistance of cacao to Crinipellis perniciosa. Plant Dis. 79: 787-791.

Ganesh D, Petitot A-S, Silva MC, Alary R, et al. (2006). Monitoring of the early molecular resistance responses of coffee (Coffea arabica L.) to the rust fungus (Hemileia vastatrix) using real-time quantitative RT-PCR. Plant Sci. 170: 1045-1051.

Gesteira AS, Micheli F, Ferreira CF and Cascardo JC (2003). Isolation and purification of functional total RNA from 
different organs of cacao tree during its interaction with the pathogen Crinipellis perniciosa. Biotechniques 35: 494-500.

Gesteira AS, Micheli F, Carels N, Da Silva AC, et al. (2007). Comparative analysis of expressed genes from cacao meristems infected by Moniliophthora perniciosa. Ann. Bot. 100: 129-140.

Gurr SJ and Rushton PJ (2005a). Engineering plants with increased disease resistance: what are we going to express? Trends Biotechnol. 23: 275-282.

Gurr SJ and Rushton PJ (2005b). Engineering plants with increased disease resistance: how are we going to express it? Trends Biotechnol. 23: 283-290.

Jalali BL, Bhargava S and Kamble A (2006). Signal transduction and transcriptional regulation of plant defense responses. J. Phytopathol. 154: 65-74.

Journot-Catalino N, Somssich IE, Roby D and Kroj T (2006). The transcription factors WRKY11 and WRKY17 act as negative regulators of basal resistance in Arabidopsis thaliana. Plant Cell 18: 3289-3302.

Kaminaka H, Nake C, Epple P, Dittgen J, et al. (2006). bZIP10-LSD1 antagonism modulates basal defense and cell death in Arabidopsis following infection. EMBO J. 25: 4400-4411.

Laquitaine L, Gomes E, Francois J, Marchive C, et al. (2006). Molecular basis of ergosterol-induced protection of grape against Botrytis cinerea: induction of type I LTP promoter activity, WRKY, and stilbene synthase gene expression. Mol. Plant Microbe Interact. 19: 1103-1112.

Leal GA, Albuquerque PSB and Figueira A (2007). Genes differentially expressed in Theobroma cacao associated with resistance to witches' broom disease caused by Crinipellis perniciosa. Mol. Plant Pathol. 8: 279-292.

Li G, Osborne J and Asiegbu FO (2006). A macroarray expression analysis of novel cDNAs vital for growth initiation and primary metabolism during development of Heterobasidion parviporum conidiospores. Environ. Microbiol. 8: 1340-1350.

Liu Y, Schiff M and Dinesh-Kumar SP (2004). Involvement of MEK1 MAPKK, NTF6 MAPK, WRKY/MYB transcription factors, COI1 and CTR1 in N-mediated resistance to tobacco mosaic virus. Plant J. 38: 800-809.

Lopez F, Rougemont J, Loriod B, Bourgeois A, et al. (2004). Feature extraction and signal processing for nylon DNA microarrays. BMC Genomics 5: 38.

Marchive C, Mzid R, Deluc L, Barrieu F, et al. (2007). Isolation and characterization of a Vitis vinifera transcription factor, VvWRKY1, and its effect on responses to fungal pathogens in transgenic tobacco plants. J. Exp. Bot. 58: 1999-2010.

Mellway RD, Tran LT, Prouse MB, Campbell MM, et al. (2009). The wound-, pathogen-, and ultraviolet B-responsive MYB134 gene encodes an R2R3 MYB transcription factor that regulates proanthocyanidin synthesis in poplar. Plant Physiol. 150: 924-941.

Mzid R, Marchive C, Blancard D, Deluc L, et al. (2007). Overexpression of VvWRKY2 in tobacco enhances broad resistance to necrotrophic fungal pathogens. Physiol. Plant 131: 434-447.

Pandey SP and Somssich IE (2009). The role of WRKY transcription factors in plant immunity. Plant Physiol. 150: 16481655.

Purdy LH and Schmidt RA (1996). Status of cacao witches' broom: biology, epidemiology, and management. Annu. Rev. Phytopathol. 34: 573-594.

Raffaele S, Rivas S and Roby D (2006). An essential role for salicylic acid in AtMYB30-mediated control of the hypersensitive cell death program in Arabidopsis. FEBS Lett. 580: 3498-3504.

Rodrigues SM, Soares VL, de Oliveira TM, Gesteira AS, et al. (2007). Isolation and purification of RNA from tissues rich in polyphenols, polysaccharides, and pigments of annatto (Bixa orellana L.). Mol. Biotechnol. 37: 220-224.

Sarowar S, Oh HW, Cho HS, Baek KH, et al. (2007). Capsicum annuum CCR4-associated factor CaCAF1 is necessary for plant development and defence response. Plant J. 51: 792-802.

Schnell RJ, Kuhn DN, Brown JS, Olano CT, et al. (2007). Development of a marker assisted selection program for cacao. Phytopathology 97: 1664-1669.

Silva SDVM, Luz EDMN, Almeida OC, Gramacho K, et al. (2002). Redescrição da sintomatologia causada por Crinipellis perniciosa em cacaueiros. Agrotropica 14: 1-24.

Terrier N, Torregrosa L, Ageorges A, Vialet S, et al. (2009). Ectopic expression of VvMybPA2 promotes proanthocyanidin biosynthesis in grapevine and suggests additional targets in the pathway. Plant Physiol. 149: 1028-1041.

Thurow C, Schiermeyer A, Krawczyk S, Butterbrodt T, et al. (2005). Tobacco bZIP transcription factor TGA2.2 and related factor TGA2.1 have distinct roles in plant defense responses and plant development. Plant J. 44: 100-113.

Wang E (2005). RNA amplification for successful gene profiling analysis. J. Transl. Med. 3: 28.

Yang B, Jiang Y, Rahman MH, Deyholos MK, et al. (2009). Identification and expression analysis of WRKY transcription factor genes in canola (Brassica napus L.) in response to fungal pathogens and hormone treatments. BMC Plant Biol. 9: 68.

Yang YH, Dudoit S, Luu P, Lin DM, et al. (2002). Normalization for cDNA microarray data: a robust composite method addressing single and multiple slide systematic variation. Nucleic Acids Res. 30: e15. 
M.A. Lopes et al.

Supplementary material

\begin{tabular}{|c|c|c|c|c|c|}
\hline Clone & Length (bp) & Functional annotation & Species & E-value & Biological process \\
\hline SP01A04 & 329 & Zinc finger (C3HC4-type) & Arabidopsis thaliana & $2.10^{-10}$ & Unknown \\
\hline SP04H06 & 419 & GAGA-motif binding transcriptional activator & Populus trichocarpa & $1.10^{-15}$ & Development \\
\hline SP05A03 & 285 & WD-40 repeat family protein & Arabidopsis thaliana & $1.10^{-28}$ & Unknown \\
\hline SP05A11 & 332 & Zinc-binding family protein & Platanus $x$ acerifolia & $3.10^{-06}$ & Unknown \\
\hline SP06B12 & 440 & bZIP family transcription factor & Glycine $\max$ & $4.10^{-40}$ & Abiotic stress \\
\hline SP06C09 & 185 & BT2 (BTB and TAZ domain protein 2) & Arabidopsis thaliana & $3.10^{-13}$ & Development \\
\hline SP06E12 & 262 & BTB/POZ (zinc-finger) & Medicago truncatula & $4.10^{-19}$ & Unknown \\
\hline SP06F03 & 284 & Transcription regulatory protein SNF2 & Arabidopsis thaliana & $2.10^{-28}$ & Unknown \\
\hline SP06F06 & 479 & MYB transcription factor & Glycine $\max$ & $5.10^{-12}$ & Abiotic stress \\
\hline SP06G09 & 260 & Zinc finger (CCCH-type) & Arabidopsis thaliana & $3.10^{-10}$ & Unknown \\
\hline SP08A03 & 343 & Zinc finger (C3HC4-type) & Arabidopsis thaliana & $4.10^{-09}$ & Unknown \\
\hline SP08A07 & 265 & Leucine zipper protein & Gossypium hirsutum & $5.10^{-29}$ & Unknown \\
\hline SP09B11 & 248 & Putative transcription factor & Oryza sativa & $6.10^{-10}$ & Unknown \\
\hline SP09C06 & 272 & Zinc finger protein & Oryza sativa & $3.10^{-10}$ & Programmed cell death \\
\hline SP09F08 & 260 & $\mathrm{KH}$ domain-containing protein & Arabidopsis thaliana & $4.10^{-11}$ & Unknown \\
\hline SP14B01 & 535 & MYB transcription factor & Boechera divaricarpa & $5.10^{-09}$ & Unknown \\
\hline SP14D09 & 467 & WREBP-1 MYB family transcription factor & Nicotiana tabacum & $2.10^{-20}$ & Phosphate starvation response \\
\hline SP15E02 & 198 & Transcription factor WRKY & Glycine $\max$ & $9.10^{-08}$ & Abiotic stress \\
\hline SP15F06 & 514 & $\mathrm{XS}$ zinc finger domain-containing protein & Arabidopsis thaliana & $4.10^{-46}$ & Unknown \\
\hline $\mathrm{SP} 15 \mathrm{G} 02$ & 330 & MYB transcription factor & Glycine $\max$ & $3.10^{-17}$ & Unknown \\
\hline SP16D03 & 412 & Putative ripening-related $\mathrm{bZIP}$ protein & Vitis vinifera & $3.10^{-13}$ & Development \\
\hline SP21C11 & 402 & Putative zinc finger protein SHI & Arabidopsis thaliana & $5.10^{-26}$ & Biosynthesis of gibberellins \\
\hline SP33C04 & 397 & Putative transcription activator & Oryza sativa & $2.10^{-32}$ & Unknown \\
\hline SP34A09 & 619 & TAFIII 15 transcription factor & Arabidopsis thaliana & $1.10^{-52}$ & Abiotic stress \\
\hline $\mathrm{SP} 35 \mathrm{C} 04$ & 489 & Zinc finger (DNL type) & Arabidopsis thaliana & $9.10^{-27}$ & Unknown \\
\hline SP35E08 & 415 & WRKY transcription factor 10 & Nicotiana tabacum & $6.10^{-10}$ & Unknown \\
\hline SP36D07 & 437 & Basic helix-loop-helix (bHLH) family protein & Arabidopsis thaliana & $8.10^{-23}$ & Unknown \\
\hline $\mathrm{SP} 37 \mathrm{C} 08$ & 433 & Zinc finger (C2H2 type) protein (WIP3) & Arabidopsis thaliana & $3.10^{-26}$ & Unknown \\
\hline SP41D03 & 318 & SPL1 (squamosa promoter-binding protein) & Arabidopsis thaliana & $4.10^{-33}$ & Unknown \\
\hline SP44B11 & 420 & Zinc finger protein & Arabidopsis thaliana & $2.10^{-07}$ & Development \\
\hline SP44H03 & 352 & $\mathrm{C} 2 \mathrm{H} 2$-type zinc finger & Picea abies & $6.10^{-39}$ & Unknown \\
\hline SP46A01 & 441 & Zinc finger (CCCH-type) & Arabidopsis thaliana & $1.10^{-14}$ & Unknown \\
\hline SP46B07 & 302 & Polypeptide-associated complex NAC & Medicago truncatula & $4.10^{-04}$ & Unknown \\
\hline SP46C08 & 418 & Protein-associated phosphoprotein Dr1 & Arabidopsis thaliana & $8.10^{-51}$ & Unknown \\
\hline SP47C07 & 404 & Zinc finger (CCCH-type) & Arabidopsis thaliana & $1.10^{-33}$ & Unknown \\
\hline SP47E01 & 382 & KH domain-NOVA, binding protein & Medicago truncatula & $2.10^{-14}$ & Symbiosis Rhizobium \\
\hline SP47E11 & 494 & MYB transcription factor & Arabidopsis thaliana & $1.10^{-25}$ & Unknown \\
\hline SP49G08 & 808 & WD-40 repeat protein (MSI4) & Medicago truncatula & $9.10^{-120}$ & Unknown \\
\hline SP61D10 & 443 & THUMP domain-protein & Arabidopsis thaliana & $9.10^{-61}$ & Unknown \\
\hline SP61E06 & 376 & NPR1/NIM1-interacting protein 1 (NIMIN-1) & Arabidopsis thaliana & $1.10^{-04}$ & Unknown \\
\hline SP61F10 & 224 & Zinc finger (C3HC4-type RING finger) & Arabidopsis thaliana & $2.10^{-18}$ & Unknown \\
\hline RT01D10 & 536 & TCP family transcription factor & Arabidopsis thaliana & $3.10^{-30}$ & Morphogenesis \\
\hline RT01E10 & 367 & Putative regulator of nonsense transcript & Oryza sativa & $1.10^{-62}$ & Unknown \\
\hline RT02D02 & 509 & MYB family transcription factor & Arabidopsis thaliana & $2.10^{-32}$ & Unknown \\
\hline RT02F02 & 469 & Transcription factor (E2F) & Chenopodium rubrum & $4.10^{-28}$ & Control of cell cycle \\
\hline RT04E12 & 400 & WD-40 repeat family protein & Arabidopsis thaliana & $2.10^{-46}$ & Unknown \\
\hline RT04G04 & 239 & Zinc finger (C3HC4-type RING finger) & Arabidopsis thaliana & $9.10^{-16}$ & Unknown \\
\hline RT05C05 & 336 & MYB-related & Craterostigma plantagineum & $5.10^{-31}$ & Tolerance to stress \\
\hline RT05H08 & 380 & Putative leucine zipper protein & Gossypium hirsutum & $8.10^{-18}$ & Unknown \\
\hline RT06D01 & 489 & PHD-type zinc finger protein & Arabidopsis thaliana & $3.10^{-16}$ & Unknown \\
\hline RT06F08 & 396 & Transcription factor & Vicia faba & $6.10^{-28}$ & Unknown \\
\hline RT07C08 & 405 & ZF-HD homeobox protein & Flaveria bidentis & $4.10^{-22}$ & Unknown \\
\hline RT08G05 & 405 & bHLH family protein & Arabidopsis thaliana & $2.10^{-40}$ & Development \\
\hline RT08H01 & 168 & PHD finger transcription factor & Arabidopsis thaliana & $3.10^{-04}$ & Unknown \\
\hline RT09D12 & 390 & Ethylene responsive element binding protein 1 & Gossypium barbadense & $1.10^{-21}$ & Unknown \\
\hline RT09F03 & 446 & WD-40 repeat protein (MSI3) & Gossypium hirsutum & $2.10^{-80}$ & Unknown \\
\hline RT10C01 & 264 & Zinc finger (AN1-like) family protein & Brassica rapa & $7.10^{-05}$ & Unknown \\
\hline RT13F06 & 449 & Transcription activator (GRL2) & Oryza sativa & $4.10^{-04}$ & Unknown \\
\hline RT14D05 & 562 & Polypeptide-associated complex (NAC) & Arabidopsis thaliana & $5.10^{-23}$ & Development \\
\hline RT15F07 & 458 & AREB-like protein & Lycopersicon esculentum & $3.10^{-46}$ & Unknown \\
\hline RT15H07 & 210 & Zinc finger protein-related & Arabidopsis thaliana & $2.10^{-05}$ & Unknown \\
\hline
\end{tabular}

Continued on next page 
Supplementary material. Continued.

\begin{tabular}{|c|c|c|c|c|c|}
\hline Clone & Length (bp) & Functional annotation & Species & E-value & Biological process \\
\hline RT16B04 & 518 & Basic helix-loop-helix protein (bHLH) & Sesamum indicum & $4.10^{-31}$ & Development \\
\hline RT16G11 & 446 & ATBPM1 (BTB-POZ and MATH domain 1) & Arabidopsis thaliana & $2.10^{-62}$ & Unknown \\
\hline RT19A02 & 461 & Transcriptional regulator-related & Arabidopsis thaliana & $9.10^{-49}$ & Unknown \\
\hline RT19B02 & 446 & MYB family transcription factor & Arabidopsis thaliana & $6.10^{-11}$ & Unknown \\
\hline RT25D12 & 318 & CCR4 associated factor 1-related protein & Capsicum аппиит & $7.10^{-06}$ & Plant defense \\
\hline RT26F08 & 440 & HB2 homeodomain protein & Populus tremula $x$ Populus tremuloides & $3.10^{-47}$ & Unknown \\
\hline RT27G02 & 477 & Transcription factor Hap5a & Medicago truncatula & $2.10^{-19}$ & Unknown \\
\hline $\mathrm{RT} 28 \mathrm{C} 03$ & 449 & Zinc finger (B-box-type) family protein & Arabidopsis thaliana & $6.10^{-36}$ & Unknown \\
\hline RT28E04 & 415 & ZF-HD homeobox family protein & Arabidopsis thaliana & $1.10^{-23}$ & Development \\
\hline RT28E07 & 394 & Putative transcription factor APFI & Oryza sativa & $2.10^{-55}$ & Unknown \\
\hline RT35D03 & 246 & $\mathrm{XH} / \mathrm{XS}$ domain-containing protein & Arabidopsis thaliana & $4.10^{-15}$ & Unknown \\
\hline RT37A04 & 123 & bZIP2 protein & Petroselinum crispum & $7.10^{-05}$ & Unknown \\
\hline RT37F09 & 132 & ZF-HD homeobox protein & Flaveria bidentis & $7.10^{-14}$ & Unknown \\
\hline RT42C09 & 500 & bZIP DNA-binding protein HBF-1 & Glycine $\max$ & $1.10^{-54}$ & Plant defense \\
\hline RT43H02 & 448 & WRKY transcription factor & Glycine max & $3.10^{-27}$ & Plant defense \\
\hline RT44F09 & 395 & Zinc finger (C2H2-type) family protein & Arabidopsis thaliana & $4.10^{-35}$ & Unknown \\
\hline RT46D05 & 416 & MYB-related protein & Dendrobium sp & $6.10^{-18}$ & Unknown \\
\hline RT49A12 & 470 & bZIP protein DPBF3 & Malus $x$ domestica & $4.10^{-32}$ & Unknown \\
\hline RT49D12 & 244 & Zinc finger protein family-like & Arabidopsis thaliana & $9.10^{-08}$ & Unknown \\
\hline RT50B08 & 416 & Myc-like regulatory protein & Citrus sinensis & $2.10^{-26}$ & Unknown \\
\hline RT050F05 & 374 & Transcription factor EREBP-like protein & Gossypium barbadense & $8.10^{-13}$ & Unknown \\
\hline RT50G06 & 395 & Zinc finger (C3HC4-type RING finger) & Arabidopsis thaliana & $1.10^{-11}$ & Unknown \\
\hline RT50H06 & 437 & bHLH family protein & Nicotiana tabacum & $5.10^{-40}$ & Unknown \\
\hline RT51G11 & 290 & Zinc finger (C3HC4-type RING finger) & Arabidopsis thaliana & $9.10^{-22}$ & Hydric stress \\
\hline RT55A06 & 367 & WD-40 repeat family protein (LEUNIG) & Antirrhinum majus & $1.10^{-51}$ & Development \\
\hline RT57A09 & 323 & bZIP transcription factor ATB2 & Glycine max & $2.10^{-26}$ & Salt and freezing tolerance \\
\hline RT59E10 & 478 & Putative transcription factor & Arabidopsis thaliana & $4.10^{-24}$ & Unknown \\
\hline
\end{tabular}

